\title{
The use open source-based virtual laboratory module to improving the student's understanding of electronic industry concept
}

\author{
Hamonangan Tambunan, Binsar Panjaitan \\ Electrical Engineering Educational Department, Technical School, State Unversity of Medan, Indonesia
}

Email address:

hamotam@gmail.com (H. Tambunan), Panja-B@gmail.com (B. Panjaitan)

\section{To cite this article:}

Hamonangan Tambunan, Binsar Panjaitan. The Use Open Source-Based Virtual Laboratory Module to Improving the Student's Understanding of Electronic Industry Concept. Education Journal. Vol. 3, No. 4, 2014, pp. 239-244. doi: 10.11648/j.edu.20140304.16

\begin{abstract}
This study examines the effect of open source-based virtual laboratory module on students' understanding of electronic industry concept. Module had previously built through the process research and development. A pre-test and post-test quasi-experimental design was used. Participants in the study were 68 students of vocational high school (36 in the experimental group and 32 in the control group). While the experimental group students were studying the concept of electronic industry, the same instruction was carried out with practical guide with the control group students. A 15 multiple choice concept of electronic industry achievement test and a 15 open ended item learning levels of electronic industry concept test were used as pre-test and post-test. The result of covariance analysis showed that the experimental group out performed the control group not only in academic achievement but also in levels of learning electronic industry of concept.
\end{abstract}

Keyword: Open Source Based Virtual Laboratory Module, Electronic Industry Concept

\section{Introduction}

As a result of dramatic changes in vocational education around the world, Indonesian Vocational High School Curricula have changed in the light of new mandates in 2013. Previous curricula were under the hegemony of a set of facts, formulas and procedures. Current curricula focus on the processes of exploration, communication and conceptualisation through the classroom activities rather than presenting a plethora of facts in traditional ways. The aim of the reform is to build a deep-rooted knowledge. In contrast with traditional classroom activities that emphasise repetition, practice, and other routinised means to reach some focused endpoint. Electronic industry concept instruction emphasises student engagement in situated electric problem-solving [1].

Recently, computer technology has emerged as a tool facilitating an important paradigm in the development of electronic industry curricula, suggesting its effectiveness for accomplishing new demands in vocational education $[2,3]$. Accordingly, the use of computers in electronic industry concepts instruction has become a basic element in the Indonesian educational system, not as a standalone resource but as an integral part of the teaching/ learning environment. The use of open source based virtual laboratory module has been especially emphasised as an important catalyst for achieving desired objectives. Instructional materials delivered using multimedia devices (sound; images / graphics and animation) and learning software, such as Matlab, Electronic Workbench, LegoCAD, and Car Builder, Multisim, ETAB, PSIM, Macromedia Flash, Easy Java Simulations (Ejs ) which has been designed so that it looks virtually the learning activity, but the activity in the laboratory study appear to be actual [4]. The advantages of this study are; (1) can explain the concept properly, (2) there is no time limit on the use of (free to access), (3) be able to perform an interactive (simulation), (4) has the innovation and development with the use of less maintenance than the actual laboratory but have to use a supplement to the high quality of learning, (5) the risk of the use was small, (6) through the actual experience of the simulation method can perform an experiment with a scientific approach, (7) increase learning productivity with a relatively short time and high learning outcomes, (8) can be used to enable collaboration and (9) can be used in developing more specific abilities .

Virtual laboratory provides a framework of comparable scientific work and training directly, although it has a 
different format to the actual circumstances but have the same experience and to help the students to acquire knowledge of concrete to abstract concepts through experimentation, and to increase interest and motivation students to learn. Virtual Laboratory (Virlab) is as an interactive object open source software that consists of heterogeneous formats and includes text, hypertext, sound, images, animation, video, and graphics are done in virtual form through a computer-based learning system. It is the potential to deliver significant improvements and more effective learning experience because it can facilitate the occurrence of deeper learning in model-based domain knowledge $[5,6]$.

The development of computer simulation techniques are so advanced in a more effective and efficient so as to allow use in teaching the concept because, this teaching is good teaching techniques as a supplement. Time required is also frugal, interactive learning can also be created [7].

To motivate students to develop the knowledge, integrate information, improve transfer of learning, learning by involving the computer is better. Scientific thinking and critical thinking will wake up and this facility can help teachers in their role as facilitators.Students learn as a result of doing or experiencing an event that experience, and learning occurs because there is a mental activity involved with physical activity $[8,9,10,11]$. The use multisim in the development and implementation of electronic science laboratory learning and conventional learning experiments on lab experience that directly use the tool / actual materials in the laboratory as effective. This is evident from the results of student achievement [12, 13].

Because many electronic circuits are oriented to the output produced, so need to know quickly the results of its output. In addition, the analysis calculations require so much time and effort, and also very broad scope of electronic circuits and constantly changing according to the need for the desired state, then open source based virtual laboratory module is required by taking into account, namely (1) conceptual change, (2) development skills, (3) the depth of knowledge of the content (content area knowledge).

The software is developed in a joint effort, with no formal coordination, using the freely available source code, and distributed via the Internet and can always be modified by the concept of copyleft, which essentially adopts the principle of copyright, but the principle is used to ensure the freedom to create is an open source. Soft ware can be used in the development of virtual learning labaoratory significantly advantageous in terms of cost and pedagogy. The module is provided as a supplementary learning tool that is flexible and can improve learning outcomes $[14,15$, $16]$.

Development of a software-based instructional media open source is done in four basic stages, namely: 1) planning, planning of data relating to the media based curriculum and instructional goals, 2) instructional design, planning is realized in draft form, 3) prototype, designed and then realized in the form of prototypes and 4) test, the prototype is tested, testing is done to test the reliability, validity and objectivity of media.

\section{Methodology}

This study was a qualitative research in which case study design was used. The reason for using case study method is that case studies enable the researcher in-depth and rich data collection $[17,18,19]$. The participants were 36 students enrolled in open source based virtual laboratory module related electronic industry in Vocational High School in North Sumatra Indonesia. About $44 \%$ of the participants are male and about $56 \%$ of the participants are female. The participants were selected according to the requirements of study [20] and they attend their courses through online. Education environment supported by online web conferencing solution. In related online learning environment, students could share their sounds and images by asking to speak with the permission of the instructor, and could communicate with each other and with the instructors in writing through chat box. In the list of participant, the students and the instructors who were present in the lesson at that moment were listed. In "Share" section in the environment, instructor could share digital objects (slides, animation, video, files, etc.), desktop and a screenshot of any application currently running and all students could see the current sharing simultaneously. Also, students could perform the same functions after the authorization of the instructor. More than one student could connect to system as voice and video and they could share.

In the study, the online electronic industry course participants enrolled was investigated. The online electronic industry courses were recorded and the shared materials were stored in the content management system. Course records and instructional materials were accessible to the students after the end of the courses in a few days. In the online electronic industry course, open source virtual laboratory module offered them to the online demonstration in online learning environment was used.

This study was taken a total of 16 weeks. In the online electronic industry course, the instructor did not use module by the time fourth week. Then, the instructor started using module in the $5^{\text {th }}$ week and the participants in the 9th week of the study. All participants were allowed to use modle. In accordance with the purpose of the study, an open-ended questionnaire was applied to the participants in the $4^{\text {th }}$ week of the study. In the study, qualitative semistructured interview form including 10 open ended questions was designed by the authors. The interviews were conducted face to face with seven participants and with 25 participants they were carried out in online media. According to [21], online interviews can performed synchronously through instant communication systems or asynchronously through e-mail. The online interviews were carried out using Skype and Adobe Connect online web conferencing media. The interviews were recorded digitally 
and transcribed by the authors. Researchers examined the records of the electronic industry courses in online education as well as semi-structured interviews and observed the participants during the study. Thus, it was aimed to ensure the data diversity and test the consistency of the data [22]

Data were analyzed using content analysis approach. First of all, the researchers transcribed recordings by converting into text data. The raw data were read three times to explore general sense of the data. Then, the researchers coded data separately and themes were determined. The researchers encoded data separately. Thus, the coder consistency was tested. Themes were re-revised and the data were interpreted. After data analysis process, the qualitative data obtained from interviews were sent to the participants in order to ensure member checking for establishing the study's credibility [23]. In order to determine the credibility and transferability of the study, unbiased and objective researcher observations were carried out, data were allowed to be checked by the participants and direct quotations from participants' statements were taken. In order to ensure the trustworthiness of the study (consistency and verifiability), as it was stated by [24] and [25], triangulation was used by applying observation and interview methods together. Attention was paid to the co-observer consistency. However, the raw data were read to the researchers three times and records of data analysis process were kept.

In qualitative studies, the implementation of the code of ethics, privacy, and noting voluntary basis is very important $[26,27]$ In this study, the participants took part in the study on a voluntary basis. As for the images used in this study, permission was obtained from both the participants and the related instructor. When they quoted from the participants opinions, names were kept confidential and encoded in the [K, number] form. During the interviews, the researchers behaved objectively, and avoided router attitudes and expressions towards participants. It was guaranteed to the participants that the data obtained during the study period were not be used excluded from the research.

\section{Results}

The results of the study were examined in two separate sections as before and after using module, to bring out the impact of using module on the students more clearly. In the semi-structured interviews, the students were asked open ended questions to state their general opinions about their 4-week online electronic industry course without using module, and their assessment about the course in the context of interaction, feedback and motivation. Analyzing the answers given by the students, it was stated that the findings before the use of virtual laboratory module were grouped into three themes as "the problems experienced in the course", "alternative solutions" and "perceived constraints".
Table 1. Results related to the findings before using module and theme

\begin{tabular}{lll}
\hline Theme & Freq & Percent \\
\hline $\begin{array}{l}\text { The problem experienced in the course } \\
\begin{array}{l}\text { Display of electronic industry scope problem } \\
\text { Feedback problem }\end{array}\end{array}$ & 26 & $81.3 \%$ \\
$\begin{array}{l}\text { Alternative solution } \\
\text { Sharing knowledge by students }\end{array}$ & $53.1 \%$ \\
$\begin{array}{l}\text { The provision of assistance by the teacher } \\
\text { Perceived constraints }\end{array}$ & 28 & $87.5 \%$ \\
Lack of interest and motivation & 19 & $59.4 \%$ \\
Lack of Interaction Feeling & 12 & $37.5 \%$ \\
\hline
\end{tabular}

The participants frequently stated that they had difficulties in the process in which both they and the instructors did not use module. Most of the participants $(81.3 \%)$ declared that they had problems in displaying the electronic industry scope problem in electronic industry courses in online education environment. "...we have difficulties in writing the symbols, formulas and signs not exist on the...", "I had a problem in the expression of electronic symbols. For example, I couldn't draw a symbol of triac and diac. "It is really hard to express the answer and solution of the question in writing in virtual media and it makes the solution nonsense". In the observation of the electronic industry courses, it was seen that students tried to express themselves through "chat box" and they had difficulties in expressing electronic symbols.

Most of the participants $(53.1 \%)$ stated that feedbacks to the questions they asked to the instructor in the learning environment were insufficient and this constituted a barrier to understand the current topic: "We were asking what we couldn't perceive in difficult problems to the teacher. It was likely that the teacher couldn't understand where we asked. Because, we couldn't see the operation steps.". "we had problems while the teacher was explaining the misunderstood parts. I couldn't get full answer for some of the questions. It seemed that there was a communication gap between us."

Most of the participants expressed that they developed alternative solutions such as the provision of assistance by the teacher $(59.4 \%)$ and sharing knowledge by students $(87.5 \%)$ and they tried to apply these solutions when the problems arose in their courses to overcome the problems they had in electronic industry classes: "I had to ask certain question parts or points of what I couldn't' understand verbally connected to the system. It was time consuming but you now I had no choice." and "I solved the asked question but how I would show it...then I opened module system. I solved it there. Both my friends and teacher saw it. Besides this I solved a problem on a paper and took the photo of it. I sent it to the teacher"

For example, testing a circuit with a module, the lecturer given the related course allowed the other students simultaneously to see operation steps of the question asked at that moment and solved by a student. It was seen that alternative solutions stated by the participants were often used in researcher observations, also. For example; a 
student connected to the learning environment from his house solved the electronic industry problem asked by the teacher on a paper, took the photo of the solution paper and using "Desktop Image Sharing" function of the system, he shared it on the media and told how he solved the problem verbally. Researcher in his observations concluded that the practices carried out by the students as alternative solutions were time wasting and decreased the control of the course.

As of the 5th week of the study, the instructor who gave electronic industry course through online education started using of virtual laboratory module. On the other hand, participants started using module in the 9th week. At the end of the study, 10 open ended questions; how virtual laboratory module in electronic industry classes in the current learning environment effects interest and motivation, interaction, instructor's feedbacks, the course process, advantages and disadvantages of functions of virtual laboratory module were asked. When the gained qualitative data were analyzed, it was seen that the findings were grouped under three themes. The frequency and percentage values for the code and themes are presented in Table 2.

Table 2. Findings Related to the Process of Using Module and Themes

\begin{tabular}{lcc}
\hline Themes & Freq. & Percent \\
\hline Interest of electronic industry Course & & \\
Participation & 14 & $43.7 \%$ \\
Willingness & 21 & $65.6 \%$ \\
Comparison of Learning Environment & & \\
Student's Role & 13 & $40.6 \%$ \\
Teacher's Role & 8 & $25 \%$ \\
$\begin{array}{l}\text { Contribution to learning process of electronic industry } \\
\text { Representation of symbols and problem }\end{array}$ & \\
solving steps & 26 & $81.2 \%$ \\
Feedback & 16 & $50.0 \%$ \\
Interaction & 14 & $43.7 \%$ \\
\hline
\end{tabular}

In the interviews after the courses where virtual laboratory module used, the participants frequently emphasized that it had a significant contribution to the learning process. Especially, it was stated that it eased the presentation and feedback of process steps and electronic symbols, increased interaction. With the contribution of it, courses were more active, also. For example; three of the participants regarding to presentation of process steps and electronic symbols expressed their thoughts as follows; "I had wrote the answers of solved questions to the teacher. Unfortunately time was completed until we would write. But with virtual laboratory module, my teacher and friends could see my solution from beginning to end. They asked questions whenever they wanted" , "it couldn't be understood exactly when the solution was told verbally but everybody could see it immediately when we used module. With module, it was very easy to project any electronic industry problem with its symbols and steps on a screen" and "as it was easy to draw symbols and expressions on a paper, I could express symbols that I couldn't write before to my teacher and friends and I showed whatever I couldn't understand before step by step to my teacher"

While two of the participants, regarding the feedback expressed their opinions as follows; "using virtual laboratory module, I could ask the misunderstood points neatly and I could get more clear answers from teacher.Mutual misunderstandings were removed." and "...it could draw shapes. Thereby my teacher could not only understand the question I asked clearly and answer it without wasting time but also he could point out the errors I made in problem solving. This was the most important benefit for me. I could understand immediately,too." Another participant said that "...it created a better interaction between $u$ s and the teacher in

lessons. I could understand the lessons better and communicate what I know comfortably. It was good'. It was mentioned that using virtual laboratory module in online electronic industry courses increased students' interests and participations. In researchers' observations, also, it was seen that students' participation level increased in online electronic industry courses in which module was used, students were more willingly to the course and asked more questions to the teacher, and sent less message about extracurricular topics. Most of the participants (65.6\%) expressed that the use of a virtual laboratory module increased the willingness and interest in online mathematics. "... virtual laboratory module increased interest towards the course fairly. It was both intriguing and very helpful indeed. I sometimes studied electronic industry over the nights. I was looking forward the fallowing question to answer it promptly."] and "courses were more enjoyable. It was a different media and useful. I could say that my motivation increased. I thought my friends were so. Because we needed to show what we think comfortably. This module enabled it". $43.7 \%$ of the participants stated that the use of virtual laboratory module in related courses increased participation: "like all my friends, when compared the previous weeks, I started not to miss especially the electronic industry class. Because I began to like Electronic Industry Course. I meant that I studied more by means of this module." And the "virtual laboratory digital provided students to participate in the course, be more active and follow the course"

In the interviews, the participant expressed their opinions about comparison of electronic industry courses in online distance education and traditional face to face classroom environment in terms of student and teacher roles. Participants stated that online education students using virtual laboratory module were more advantageous compared to the students in formal education. It was emphasized that onlne education students were more advantageous as they connected to the learning environment with virtual laboratory could be seen both by students and by teacher simultaneously: "For example compared to the formal students, I could solve problems more comfortably and show them to my teacher and friends. I did not feel the pressure and anger while solving on the whiteboard in front of everybody. As to me, online 
education students were more comfortable in this issue", "According to the formal online education courses inelectronic industry processed with a virtual laboratory module and process your electronic industry class, I think it melts the difference between us and our students in formal education course, according to them, allows us to be more active”. $25 \%$ of the participants mentioned that school members in electronic industry courses could not experience the complications that experienced in the traditional classroom environment and they could have more effective courses. Relative participants expressed their opinions as follows: "In formal education environment, board was used. While using the board, teachers and students were back to back and there wasn't communication. Whereas, in online education, teacher using virtual laboratory module could write and see in the same time and students could see what the teacher simultaneously. I thought this relaxed the teacher more", "In online education environment, our teacher could make more activities and group works. And what he wrote could be seen by everybody. He could see and control immediately. Our learning was more advantageous compared to the environment in formal education".

The results of the interviews with the participants were matching with the results in the researcher's observations. It was seen that alternative practices that students tried to do before using virtual laboratory module were time consuming and made the classroom management difficult in terms of school member. Performed observations seemed to support the statements of the participants.

\section{Discussion and Conclusion}

In many virtual lab studies in the literature, it was realized that opensource based virtual laboratory were used to ease classroom interaction and communication in faceto-face learning environments. In this study, virtual laboratory module, one of the modules was used in online electronic industry course by online students and using the virtual laboratory module in the online electronic industry course was evaluated from the distance students' perspectives. It was seen that when supporting technologies as virtual laboratory module wasn't used, students used entirely a different language instead of electronic industry expressions and both students and teachers had ambiguity for these answers. Also it was stated that answering the questions with keyboards that provide only alphabetic and numeric entry caused problems in learning environment.

It was concluded that virtual laboratory module enabled students and faculty members to express themselves electronically more comfortable. It was seen that school member and students could easily transferred and used their own hand writings to digital media with virtual laboratory module in online electronic industry courses, special electric measurement expressions and electronic formula could be easily shared in classical classroom environments. Similarly, [28] indicated that slides could not respond to instantaneous needs in face-to-face. And also, virtual laboratory allowed electronic handwriting while explaining elactronic industry content to the students. In another study, attention was drawn to fact that electronic industry content (graphics, shapes, etc.) could be written electronically, and thus it had a positive effect on education and training [29].

It was underlined that before using the virtual laboratory module in online education environment in the study process, students had many problems in participating actively in course. In order to overcome the problem, online education students preferred to share eletrical problems in the media by solving them on a paper and scanning them or taking their photos and writing them with a keyboard. In this case, transfering the solution to digital media or overcoming microphone problems caused loss of time and this loss of time distracted the attention and reduced the students' attention. It was seen that while presenting in face to face classroom environment, if school member stood in front of the projection device, students couldn't see writings and their attention would distract; in online education environment, simple audible expression or using slides caused loss of time.

Based on the research findings, it can be concluded that by using the virtual laboratory modules in the online education environment can improve the interaction between students and teachers, and are able to provide timely feedback and promote student participation. The results of this study are consistent with the results of research that allows students to answer the questions with their own handwriting and allow teachers to give good feedback for this response [30]. Also in this study, it was concluded that as using virtual laboratory module in online electronic industry course decreased loss of time, prevented distraction and provided active participation, it increased students' interest to the course. Similarly, in another study, it was concluded that using the relevant technologies made participants active, it increased student motivation [31]. As a result, it can be said that enabling virtual laboratory module to use by online students and online electronic industry teachers is very important to facilitate interaction and learning electronic industry in online electronic industry courses. A training program can be designed for distance students and online electronic industry teachers not to have problems in using virtual laboratory module integrated in online education environment. There are several limitations to the study. First, the findings of the study are based on a total of 32 online students' perspectives. Second, study process was short time for a qualitative study. For further research, it is necessary to investigate using a virtual lab with other students online in a longer process.

\section{Acknowledgements}

We would like to thank the Ministry of Education and Culture of Indonesia, especially Directorate of Higher Education, for funding this research. 


\section{References}

[1] Lou, Shi-Jer et al. How to Promote Knowledge Transfer through a Problem-Based Learning Internet Platform for Vocational High School Students. European Journal ofEngineering education, 35(5). Oct 2010. 539-551.

[2] Miller, Linda Wise. Computer integration by vocational teacher educators. Journal of Vocational and Technical Education, Volume 14, Number 1, 1997. http://scholar.lib.vt.edu/ejournals/JVTE/v14n1/JVTE-3.html.

[3] Meridian. Developing Vocational Education through Computer Literacy in Nigerian Junior Secondary School Curriculum. A Middle School Computer Technologies Journal a service of NC State University, Raleigh, NC Volume 10, Issue 2, $2007 . \quad$ ISSN 1097-9778. http://scholar.lib.vt.edu/ejournals/JVTE/v14n1/JVTE-3.html.

[4] Agnes et al. Instructional Technology for Teaching and Learning. New Jersey: Prentice Hall. 2000.

[5] Jeschke, Richter and Seiler. General framework for Virtual Laboratory. The 2nd Cracow Grid Workshop, Cracow, Poland. 2005.

[6] Reilly J J et al. Objective measurement of physical activity and sedentary behaviour: review with new data. 2008. Online: http://adc.bmj.com/content/93/7/614.short.

[7] Ghassemlooy, M., Harsányi, G., Ripka, G.; Becsek, J., Pinkola, J., Králik, D. and Szikora, B. Laboratory Background of Electronics Technology Practices. Proceedings of the 15th International Spring Seminar on Electronics Technology, Herlany (Slovak Republic), May 11-14, 1992, in Transactions of the Technical University of Kosice, Vol. 3, No. 1, 2000. pp. 61-63.ISSN 09606076.

[8] Rivers, R. H., and Vockell, E.Computer simulations to stimulate scientific problem solving. Journal of Research in Science Teaching, 24(5), 1987. 403-415.

[9] Wilkinson, John W. and Ward, Malcolm. The purpose and perceived effectiveness of laboratory work in secondary schools. Australian Science Teachers Journal;, Vol. 43 Issue 2 June 1997, p49

[10] Magnusson. Development of Multimedia Modules for Education. Computer Applications in Engineering Education, Vol. 3,No. 2.1995.

[11] Smith, Esquembre."Easy Java Simulations versi 3.4", Universidad de Murcia. Spain. 2002.

[12] Hackworth. Uncovering the creative dimensions of computer-graphic design products. Creativity Research Journal, 5 (3), 2002. 233-243.

[13] Y. B. Gandole, S. S. Khandewale and R. A. Mishra. A Comparison Of Students' Attitudes Between Computer Software Support And Traditional Laboratory Practical Learning Environments In Undergraduate Electronics Science Department Of Electronics, e-Journal of Instructional Science and Technology (e-JIST) .Vol. 9 No. 1, March 2006.

[14] Song, Xueshu et al. AVirtual laboratory for machine Tool Operations and maintenance Engineering Technology.
International Journal Of Instructional Media Vol 35 (2), 2008.

[15] Ndahi, B Hasan et al. Engineering education: Web based interactive learning resource. The echnology Teacher. 2007.

[16] Chen, Li-Chiou \& Tao, Lixin. Teaching Web Security using Portable Virtual labs. Journal of Educational Technology and Society 15(4). 39-46.2012.

[17] Yin, R. Case study research: Design and methods (2nd ed.). Thousand Oaks, CA: Sage Publishing. 1994.

[18] Patton, M. Qualitative research and evaluation methods (3rd ed.). Thousand Oaks, CA: Sage Publications. 2002.

[19] Creswell, J.W. Qualitative inquiry and research design: Choosing among five traditions (2nd Ed). Thousand Oaks, CA: Sage. 2007.

[20] Morse, J.M. Strategies for sampling. In J. Morse (ed.), Qualitative nursing research: A contemporary dialogue, (pp. 127-145). (Rev. Ed.), Newbury Park, CA: Sage. 1991.

[21] Griffiths, M. The use of online methodologies in data collection for gambling and gaming addictions. In International Journal of Mental Health and Addiction, 8(1), (pp. 8-20). 2010.

[22] Sowell, E.J. Educational research: An integrative introduction. Boston: McGraw-Hill Higher Education. 2001.

[23] Guba, G.G. and Lincoln, Y.S. Competing paradigms in qualitative research. In N.K.Denzin \& Y. Lincoln (eds.), Handbook of qualitative research. Thousand Oaks, CA: Sage. 1994.

[24] Sowell, E.J. Educational research: An integrative introduction. Boston: McGraw-Hill Higher Education. 2001.

[25] Shenton, A.K. Strategies for ensuring trustworthiness in qualitative research projects. In Education for Information, 22, (pp. 63-75). 2004.

[26] Christians, C.G. Ethics and politics in qualitative research. In N.K. Denzin \& Y.S.Lincoln (eds.), The landscape of qualitative research: Theories and Issues, (pp. 208-43). (2nd ed.), Thousand Oaks, CA: Sage Publications.2003.

[27] Miles, M.B. and Huberman, M.A. Qualitative data analysis: An expanded sourcebook (2nd Ed.). Beverley Hills: Sage. 1994.

[28] Galligan, L., Loch, B.; McDonald, C. and Taylor, A.J. The use of tablet and related technologies in mathematics teaching. In Australian Senior Mathematics Journal, 24(1), 2010. 38- 51 .

[29] Weitz, R.R., Wachsmuth, B. and Mirliss, D. The tablet pc for faculty: A pilot project. In Educational Technology \& Society, 9(2), 2006. 68-83.

[30] Dunham, Marissa Waldman et al. Instructional Design And Assessment: The Use of Virtual Laboratories and Other Web-based Tools in a Drug Assay Course. American Journal of Pharmaceutical Education 2012; 76 (5) Article 84.

[31] Casas, I., Ochoa, S.F. and Puente, J. Using tablet PCs and pen-based technologies to support engineering education. Paper presented at 13th International Conference on Human-Computer Interaction. San Diego, CA. 2009. 